\title{
Gilberto Freyre: una visión brasileña de la comunidad bilingüe panibérica
}

\author{
Pablo González-Velasco (D) @ \\ Universidad de Salamanca (USAL), España
}

Resumen. En 2020 se cumple el $120^{\circ}$ aniversario del más universal de los antropólogos brasileños: Gilberto Freyre (1900-1987). Descendiente de portugueses y españoles, el maestro de Apipucos mantuvo una actitud conciliadora entre los países de lengua española y portuguesa. Desarrollaremos sus tesis sobre el bilingüismo del brasileño y la universalidad del español y el portugués, así como sobre la potencialidad geopolítica de la base lingüística y comunicativa común. Estableceremos analogías con las concepciones paniberistas de la actualidad, basadas en el proceso de convergencia hacia una comunidad hispanohablante y lusófona sin excepciones. Analizaremos las fronteras policéntricas y pluricontinentales de la intercomprensión, la revocada ley brasileña del español y la polisemia del concepto del "bilingüismo" que dificulta la articulación de consensos diplomáticos. Palabras clave: bilingüismo; Gilberto Freyre; iberofonía; intercomprensión; hispanotropicología.

\section{Gilberto Freyre: uma visão brasileira da comunidade bilíngue pan-ibérica}

Resumo. 2020 marca o 120 aniversário do mais universal dos antropólogos brasileiros: Gilberto Freyre (1900-1987). Descendente de portugueses e espanhóis, o mestre de Apipucos manteve uma atitude conciliatória entre os países de língua espanhola e portuguesa. Desenvolveremos suas teses sobre o bilinguismo do brasileiro e a universalidade do espanhol e do português, bem como sobre a potencialidade geopolítica da base linguística e comunicativa comum. Estabeleceremos analogias com as concepções pan-iberistas de hoje, baseadas no processo de convergência para uma comunidade hispanófona e lusófona sem exceções. Analisaremos as fronteiras policêntricas e pluricontinentais da intercompreensão, a revogada lei brasileira do espanhol e a polissemia do conceito de "bilinguismo" que dificulta a articulação de consensos diplomáticos.

Palavras-chave: bilingüismo; Gilberto Freyre; iberofonia; intercomprensión; hispanotropicologia.

\section{Gilberto Freyre: a Brazilian vision of the bilingual pan-Iberian community}

Abstract. 2020 marks the 120th anniversary of the most universal of Brazilian anthropologists: Gilberto Freyre (1900-1987). Descendant of Portuguese and Spanish, the master of Apipucos maintained a conciliatory attitude between the countries of Spanish and Portuguese language. We will develop his theses on Brazilian bilingualism and the universality of Spanish and Portuguese, as well as on the geopolitical potential of the common linguistic and communicative base. We will establish analogies with today's pan-Iberian conceptions, based on the process of convergence towards a Spanish-speaking and Portuguese-speaking community without exceptions. We will analyze the polycentric and pluricontinental borders of the intercomprehension, the revoked Brazilian law of Spanish and the polysemy of the concept of "bilingualism" that hinders the articulation of diplomatic consensuses.

Keywords: bilingualism; Gilberto Freyre; iberophone; intercomprehension; hispanotropicology.

\section{Diferencias y semejanzas entre el portugués y el castellano}

El área cultural panibérica constituyó, para Gilberto Freyre, una referencia antropológica, lingüística y geopolítica crucial en su vida y en su obra. Antes de desarrollar el ideario freyriano y hacerlo dialogar con las corrientes de la actualidad, identificaré brevemente los matices y las tensiones internas del sustrato lingüistico-cultural ibérico.

Encontrar las diferencias entre ambos idiomas es una tarea mucho más sencilla que identificar las semejanzas, sin embargo, no deja de ser un ejercicio peligroso por cuenta del nacionalismo lingüístico que tiende a 
interpretaciones separadoras. Para realizar un análisis comparativo imparcial es importante pivotar sobre una tercera lengua, ya sea latina o no latina, para así calibrar con exactitud el grado de semejanza entre ambas lenguas ibéricas globales. La base lingüística común se puede desglosar en una primera base latina, a la que hay que sumar una segunda base iberromance, y, finalmente, una tercera base a consecuencia de la interpenetración lingüística en el espacio occidental peninsular, con especial intensidad simbiótica durante el periodo del bilingüismo literario. El macroespacio del iberromance occidental no posee rupturas ni fronteras sintácticas. Existe una transición lingüística gradual, entre lo luso y lo castellano, a lo largo del espacio lingüístico galaicomirandés-leonés, que va en paralelo a la Raya ${ }^{1}$ hasta Huelva.

¿Cuál es el tamaño de la base lingüística y comunicativa común, y, por ende, el grado y los canales de inteligibilidad mutua entre el castellano y el portugués? Las estructuras-lógicas de sus gramáticas, que moldean nuestra manera de articular, ordenar y expresar el pensamiento, son prácticamente idénticas, con algunas excepciones, que no ponen en riesgo la comprensión mutua entre ibéricos, como, por ejemplo: la colocación pronominal o la forma pasiva del verbo. En términos de lexemas la unidad lingüística es mayor que en términos de morfemas, pero estos no dejan de tener paralelismos inteligibles. Muchas veces lo que nos sugiere la lengua hermana, cuando entramos en contacto, es el uso preferencial de términos que en nuestra lengua están en desuso o que nuestros lexemas se manifiestan en el otro idioma de forma diferente, transformándose en adjetivos, verbos o substantivos. El contexto histórico-cultural de base hispanorromana, con influencias visigodas, judías y andalusíes, es el mismo para todo el espacio peninsular. Por tanto, tampoco hay rupturas culturales. La mayor diferencia es la fonética, y, en particular, la fonética luso-europea que puede suponer un escollo. Hablaremos más adelante sobre cómo superarlo.

La paradoja, advertida en el Idearium español, por Ángel Ganivet y citada por Freyre (2010, p. 251 [1933]), estriba en que la antipatía entre el portugués y el español no es consecuencia de sus diferencias, sino de sus similitudes. Esta interpretación histórica también puede ser aplicada a las lenguas. El exceso de semejanzas ha actuado como elemento reactivo, paradójicamente, separador, ya sea por autodefensa o ensimismamiento. La antipatía histórica ocultaba que ambos idiomas tienen más de "auténticos amigos" que de "falsos amigos".

${ }^{1}$ La frontera terrestre existente entre España y Portugal, coloquialmente llamada como la Raya, o a Raia en portugués y gallego, es una frontera de 1214 km de longitud, constituida por primera vez en la Paz de Zamora, en 1143, y cuyo trazado en la actualidad fue revisado y acordado en parte en 1926 con el Acuerdo de Límites. 
Freyre consideraba que una de las ventajas que debían y deben aprovechar los brasileños es su capacidad de leer la lengua castellana y sentirla tan materna como la portuguesa. Para Freyre no es posible entender la cultura española sin la cultura portuguesa, ni la portuguesa sin la española. No existen relaciones de extranjería cultural entre ambas partes. El maestro de Apipucos ejerció un iberismo existencial y metodológico a lo largo de su vida y obra desde sus tiempos de "estudante sul-americano no estrangeiro" en las:

universidades, as do tipo cosmopolita, em que o indivíduo no contacto com indivíduos de várias procedências, deixa de ser exclusivamente indivíduo para identificar-se profunda e empaticamente com a sua gente brasileira, nem somente com a cultura luso-brasileira, em particular, porém, - como descendente que sou, tanto de espanhóis como de portugueses há séculos integrados nos trópicos mas sempre ibéricos nos principais motivos de vida - com a gente e com cultura ibéricas, em geral; e, como tal, contente, desde adolescente, de poder ler, como não era possível a um estudante de língua inglesa ou francesa ou alemã, um Cervantes e um Luís Vives, um Gracián e um Vitoria, um Ramón Lulio e um San Juan de la Cruz, um Frei Luís de León e uma Santa Tereza, um Lope de Vega e um Calderón, como se lesse obras-primas na minha própria língua materna. Pois uma das vantagens do brasileiro que lê espanhol é esta: ter duas línguas literárias maternas, a portuguêsa e a espanhola, em vez de uma só, e poder sentirse por suas ligações europeias de origem, tão espanhol quanto português (Freyre, 1968, p. 47).

En Oxford conocerá a un grupo de hispanistas organizados en torno al Oxford Spanish Club. Gilberto será invitado a discursar sobre "dom-juanismo ibérico" en una reunión del grupo. Escribe en su diario:

Conversamos sobre autores espanhóis. Vives é aqui muito estimado. Decerto um dos motivos dessa estima é ter estado ele em Oxford, onde Ihe foi dado um título de doutor honoris causa. Está aqui muito em voga [Juan de] la Cruz. Mais que Santa Teresa. O teatro espanhol é apreciado como o maior rival (o grego estando fora de competição) do inglês. A literatura em língua portuguesa é quase ignorada pelos hispanófilos de Oxford. É como se Portugal e o Brasil não tivessem escritores. Lembrei-me a propósito daquele personagem de Eça, n'Os Maias, que pergunta a um recém-chegado da Inglaterra se entre os ingleses havia literatura. Outra não é a atitude da maioria dos ingleses para com a literatura portuguesa: ignoram que existe. É verdade que há traduções de Camões. Mas não é autor que se compare a qualquer dos espanhóis aqui lidos, estudados, admirados. $\mathrm{O}$ inglês admira a Espanha. Respeita-Ihe a literatura, a arte, a poesia, a música, a dança. Portugal é para eles uma gente simpaticamente pitoresca (Freyre, 1975a, p. 219).

Freyre consideraba que portugueses y brasileños, a pesar del temor ante un hipotético imperialismo español, no pueden renunciar a la pertenencia a un espacio lingüístico y cultural común. La renuncia es, para el antropó- 
logo brasileño, una especie de "dissidência caprichosa y sectária" como la de "aquellos católicos" que se desvinculan de Roma. La falta de alianza ibérica, según Freyre (1975a, p.118), también era por "uma tendência de alguns espanhóis a vincular o adjetivo hispânico com o espanhol. É inexato". Para Freyre (1976) lo hispánico va más allá de lo español: incluye el mundo portugués. Se regocija de la importancia del español, del privilegio de poder leer la lengua castellana y de su liderazgo entre las lenguas y las literaturas ibéricas ("a mais opulenta, valiosa e alta literatura"), pero insiste que ese reconocimiento sincero y fraternal de la importancia del español, "não significa que se deva desprezar o resto de línguas hispânicas. Cada uma delas tem sua importância. Cada uma delas tem seu próprio modo de contribuir para a grandeza e a complexidade da cultura hispânica, inclusive a língua portuguesa", que se presenta como: "uma das línguas de maior ascensão literária dentro do mundo hispânico".

En 1922, estando en Inglaterra, su identidad transnacional comienza a ser más nítida después de un proceso de autoanálisis y contraste con sus colegas. Freyre reconoce el cambio en su conciencia:

Estava eu no começo dessa minha consciência pan-ibérica de simples candidato, mal saído da adolescência, a escritor, quando em Oxford, na Inglaterra, conheci o então mestre de literaturas ibéricas naquela universidade, o Professor de Arteaga - antecessor de Salvador de Madariaga - que um dia me sugeriu permanecesse eu no burgo oxoniano como seu assistente. Sugestão que confesso ter me seduzido, de tal modo correspondia ao meu afã pan-ibérico e ao meu encanto pela vida na Oxford daqueles dias. Mais forte, porém, que esse encanto foi o meu outro empenho, também daqueles dias e que dura até hoje: o de reintegra-me no trópico de que sou nativo, não como simples brasileiro, mas como brasileiro pan-iberico (Freyre, 1968, p. 176).

Una vez de vuelta a Recife, en 1924, en plena readaptación a los trópicos después de varios años en el extranjero, Freyre (1975a; p.267) se quejará del desconocimiento de los brasileños de los "valores clássicos em língua espanhola e de modernos como Pío Baroja, Ganivet, Unamuno, Azorín, Valera, Galdós, Ortega", a pesar de la cantidad de libros en español que importaba Brasil. Tampoco se olvidará de Cervantes, de quien dirá que, como "buen hispano", su gente no era "solo la española sino también la portuguesa". Era más que español: un "español pan-ibérico", según el maestro de Apipucos (Freyre, 1968, p. 170). El autor de El Quijote diría que el idioma portugués es un "español sin huesos". Lo que, despejando la ecuación, nos daría que el español es un "portugués con huesos". La hispanofilia y la lusofilia son totalmente compatibles en la cosmovisión freyriana. Desde luego que suscribiría la opinión del escritor mexicano Alfonso Reyes (1952) cuando 
afirmaba que: "el que ama de veras la lengua castellana tiene que amar a la lengua portuguesa". Y viceversa. Es decir, se trababa de descubrir, conocer y revalorizar la lengua hermana ibérica.

\section{Bilingüismo literario y la formación del portugués brasileño}

Gilberto Freyre mantendrá una importante amistad con Fidelino de Figueiredo, a quien conocerá personalmente en 1923. Años más tarde, en 1931, Figueiredo dará un curso en el Instituto de las Españas (Hispanic Institut) de la Universidad de Columbia, a convite de otro amigo de Freyre: Federico de Onís, director de dicho centro. Los materiales del curso se convertirán en el más relevante estudio comparado de las literaturas ibéricas: Pyrene.

Figueiredo (1935) mencionará en dicho ensayo los estudios del "bilingüismo literario" de Carolina Michaëlis. Para Freyre (1953, p.83): "o bilinguismo literário parece ter sido a expressão mais completa (...) dessas constantes de interpenetração de cultura erudita na Península". Interpenetración que va más allá de la Península o de la influencia española en el portugués, dado que hay "portuguesismos em Cervantes e castelhanismos em Euclydes da Cunha" (Freyre, 1971). Estando Freyre (1953, p.80) en Elvas (Portugal), ciudad singular por su bilingüismo luso-espanhol, anotará en su diario de viaje: "Dona Carolina Michaëlis defendeu com magistral segurança a tese do bilinguismo literário na Península: duas línguas durante longo tempo estiveram a serviço da mesma cultura peninsular, uma língua preferida para as expansões líricas, outra para as afirmações épicas". Cabe recordar que hubo más de 5000 alumnos portugueses en la Universidad de Salamanca durante los siglos XVI y XVII (Rodil, 2019). La escritora brasileña de origen gallego Nélida Piñon afirmará:

El castellano, cuya intensa presencia en Portugal dio lugar a que algunos estudiosos proclamasen, con notable exageración, que existía en el país un cierto bilingüismo, es un fenómeno cultural y político que se inicia en el período conocido como Cuatrocientos, pero se consolidó dos siglos más tarde, antes de la Restauración, en torno a 1640.

Las circunstancias históricas, que en una época vincularon a las dos lenguas, ya fuera en la disputa del poder político, como en las querellas poéticas, hicieron que el castellano se convirtiera en una lengua de prestigio, ampliamente adoptada por la elite portuguesa. Una aparente simbiosis social y lingüística permitió al imaginario portugués abastecerse lentamente de autores como Calderón de La Barca, Garcilaso de La Vega, Cervantes o Lope de Vega. (Piñon, 2010). 
El bilingüismo de las élites literarias portuguesas no supuso un riesgo de diglosia general, por el monolingüismo popular e institucional. Este último fue un compromiso de Felipe II en las Cortes de Tomar (1581). No obstante, se constata una preponderancia del español en los préstamos lingüísticos ibéricos. Un escritor pan-ibérico español, como Juan Valera, gran divulgador en España de la literatura portuguesa y la poesía brasileña, considerará:

El castellano y el portugués no parecían dos idiomas diversos, sino dos formas, dos modos del mismo idioma. En la magnífica corte del rey $\mathrm{D}$. Manuel suena en prosa y en verso el habla de Castilla. El Cancionero de Resende está lleno de versos castellanos. La musa dramática portuguesa hace sus primeros felices ensayos en los Autos de Gil Vicente, muchos de ellos en castellano, y otros en castellano y en portugués mezclados y confundidos. El primer poeta lírico portugués, el justamente celebrado Sá de Miranda, escribe gran parte de sus obras en nuestra lengua; el mismo Camoens le imita y le sigue en esto (...) el llamado por los portugueses mismos príncipe de los poetas españoles (Valera, 1861).

Aquellos tiempos del bilingüismo de élites durante el periodo de la unión de coronas de la monarquía hispánica coincidió con un periodo decisivo en la formación territorial y espiritual de Brasil y de la variedad lingüística del portugués brasileño. Por tanto, no se trata de una ocurrencia la formulación de la hipótesis sobre una eventual influencia del español en la "infancia" del portugués brasileño. Misioneros hispanohablantes (como Anchieta o franciscanos castellanos), aventureros gauchos y bandeirantes, que transitaban corredores transfronterizos, son todos agentes de dicha influencia hispánica:

Con la vigencia de la Unión Ibérica, el castellano refuerza su presencia en la colonia gracias a la llegada de los españoles, de los judíos expulsados de España, a la inexistencia de la imprenta en Brasil, lo que obligaba a leer en español y portugués los libros traídos de Europa. Y gracias también al género epistolar, a la correspondencia que se intercambiaba en portugués y castellano, se refuerza esta presencia (Piñon, 2010).

En las postrimerías del Brasil hispánico, en torno al 1640, en la ciudad conocida en el cono sur hispanoamericano como San Pablo (São Paulo) se hablaba español:

São Paulo (capitanía de São Vicente en la época) era un territorio aparte, en el que la presencia de los agentes reales era muy escasa y donde el poder estaba en manos de los jesuitas y de los colonos que se organizaban en "bandeiras" para capturar indígenas y venderlos como esclavos. Era un territorio sin ley donde las lenguas más habladas eran tupí y español (Santos, 2019). 
Escavando por debajo de la segunda portuguesización traída por João VI, existe un sustrato brasileño cultural y antropológico, según Piñon (2010), "con vestigios de la presencia de la lengua española" en la "psique de Brasil", que, a pesar de la dificultad de rastrear sus influencias por los mil hilos narrativos del tejido de la cultura brasileña, difundió una "materia mítica, una cultura y posibilitó alianzas históricas". La escritora hispanobrasileña cuenta que al inventariarse los bienes de un bandeirante se encontró en su equipaje un "arrugado folleto con poemas de Quevedo".

En aquel tempo, el centro político y económico de la colonización ibérica estaba en el Nordeste. El escritor brasileño Chacon (2005) menciona "os subdialetos, ou falares, populares nordestinos brasileiros, guardam inclusive muitas palavras castelhanas, do tempo da maior proximidade coloquial com o português: "arriba", "preguntar", "entonces", "ancho" e inúmeras outras de uso ainda hoje corrente". Muchas de estas palabras Ilegaron a través del folclore popular peninsular y sus trovadores. Junto a ellas viajaron centenares de proverbios de una sabiduría popular y mestiza milenaria.

No toda influencia en el espacio panibérico fue castellanizante. Cabe reseñar la generosa y enriquecedora presencia de lusismos en las versiones de español de Uruguay, Canarias y Guinea Ecuatorial. Tampoco debemos minimizar las influencias lingüísticas y culturales transoceánicas, de ida y vuelta, es decir: de América para Europa y otros continentes.

\section{La universalidad del español y el portugués}

Freyre (1968, p.176) siempre reivindicó los valores ibéricos de una "cultura global" e "inseparable" que temprana y afortunadamente "descobri ser tão minha, assim global -minha e dos brasileiros- quanto dos espanhóis da Espanha ou dos hispano-americanos". Tan suya como la portuguesa. Brasil fue tambien "colónia outrora da Espanha", según el pernambucano.

Uno de los diálogos filosóficos, lingüísticos y antropológicos más fructíferos se desarrolló entre el brasileño Gilberto Freyre y el español Julián Marías. Naturalmente el maestro de Apipucos hablaba en portugués y el heredero de Ortega y Gasset en español. Su intercomprensión linguística era totalmente efectiva, dado que su nivel cultural era equivalente (mínima variación diastrática). En un homenaje a Gilberto Freyre en Brasilia, reflexionaría sobre la proximidad de ambas lenguas ibéricas: 
Se dirá que los pueblos ibéricos o hispánicos están separados por la lengua, primera interpretación de la realidad, instalación vital básica. Pero ¿es que la diferencia entre el español y el portugués separa? He hablado de la maravilla de que el español hace íntegramente transparentes, recíprocamente transparentes, a tantos pueblos de razas diversas. He insistido muchas veces en que no sólo se habla, sino que se vive en español, y hombres y mujeres étnicamente distintos de los españoles, con facciones diferentes, hacen gestos españoles cuando están hablando, movilizan las formas radicales de vida que se engendraron hace mil años en un rincón de Europa; y lo mismo se podría decir de la lengua lusitana y los que la hablan como propia. Pero español y portugués, si no mutuamente transparentes, son traslúcidos, responden con dos tonalidades diferentes a una misma forma de instalación, de interpretación de lo real. La lengua escrita es casi la misma; el léxico y la sintaxis, muy próximos; la fonética introduce una diferencia que se supera al poco tiempo y que no es mucho mayor que la diferencia entre dos acentos regionales; únicamente es menos familiar. La mayoría de las peculiaridades de una lengua se encuentran en la otra: la distinción entre «ser» y «estar», el impersonal y maravilloso «haber»; el diminutivo (Marías, 1981).

Marías (1983) lanzó un desafío a Freyre: investigar sobre un aspecto que le parece "decisivo" y del que Freyre "casi no insiste, tal vez por estar inmerso en él: la universalidad de la lengua portuguesa en el Brasil, a pesar de tantas mezclas y tantas vicisitudes de su inmensa y no muy vertebrada sociedad". Freyre (2001) sí que había explicado los trazos africanos del portugués de Brasil dentro de un marco cultural ibérico, pero sobre todo lo que hizo es convertir esa realidad panibéricamente universal en una proyección y responsabilidad geopolítica a ser desempeñada por el Itamarati:

todo brasileiro é bilingue: lê o português e lê o espanhol. (...) É evidente que, como o povo mais hispânico da América, é o brasileiro que deve tomar a si a responsabilidade de tornar mais hispânica não só a América, dividida com demasiado rigor em América espanhola e América portuguesa, como a comunidade hispânica em sua totalidade: também ela rigidamente dividida em espanhóis e portugueses, em descendentes de portugueses e descendentes de espanhóis, em continuadores de espanhóis e continuadores de portugueses, quando o nosso grande destino sociológico é formamos uma comunidade hispânica bilíngue multicultural, multinacional, mas articulada numa só e complexa civilização cujo ritmo, cuja cadência ou cujo tempo continue psicologicamente o mesmo; organizada, embora não ordenada nem arregimentada, num só e fraterno sistema de vida, caracterizado pelo personalismo que impeça os homens de se despersonalizarem em números; num sistema interdependente de nações orientadas pela consciência de origens comuns e de tendências, interesse e aspirações, em grande parte, comuns (Freyre, 2001). 
La "comunidade hispânica bilingue multicultural e multinacional" de Gilberto Freyre, hoy podríamos enunciarla, con el mismo significado, como una "comunidad panibérica de intercomprensión". Es decir, la plena y simultánea capacidad de comprensión del portugués y el español, usando como único recurso la propia lengua ibérica nativa. La "intercomprensión" se materializa cuando dos personas se comunican entre sí con éxito hablando cada una en su propia lengua. El proceso de comprensión recíproca entre hablantes de lenguas diferentes, si bien espontáneo, puede sin duda acelerarse a través de métodos específicos de enseñanza y de la propia globalización de las comunicaciones que ayuda a derribar las fronteras lingüísticas, especialmente a través de las redes sociales.

\section{La geopolítica de la base lingüística y comunicativa común}

La Casa Real española ha reconocido la base lingüística común y su potencialidad. En la XXVI Cumbre Iberoamericana de Guatemala, en noviembre de 2018, el rey Felipe VI afirmó:

Cada día, avanza positivamente el proceso de acercamiento entre los países hispanohablantes y lusófonos del mundo, juntos, como he señalado en otras ocasiones, conforman un gran espacio multinacional de 800 millones de personas en una treintena de países de todos los continentes. No cabe duda de que esta realidad de base lingüística y cultural contribuye a articular unas relaciones económicas y comerciales más intensas, sólidas y fluidas entre todos nuestros pueblos

Portugal ha dado señales de cambiar su política exterior, pasando de un perfil bajo en el espacio iberoamericano a tener un perfil propio e incluso un cierto activismo estratégico. Días después de la citada Cumbre Iberoamericana, el ministro de Asuntos Exteriores portugués reconocía:

A Conferência Ibero-Americana (CIB) e os seus organismos setoriais constituem, do meu conhecimento, a única entidade internacional de base linguística que se funda não numa mas em duas línguas: o espanhol e o português. E esta característica distintiva resulta do facto de, na sua génese, em 1991, ter estado a vontade de articular o conjunto da América Latina e o conjunto da Península Ibérica - isto é, de não reduzir a organização ao diálogo entre Espanha e os países saídos dos seus domínios coloniais-. Esta contribuição de Portugal para que seja o mundo ibérico europeu a relacionar-se com o mundo latino-americano seria razão bastante para a nossa política externa investir na CIB. (Silva, 2018). 
El interés portugués en Hispanoamérica es creciente por la presencia de sus emigrantes y como parte de una nueva estrategia de internacionalización del portugués y de reequilibrar el peso de la lusofonía en la Comunidad Iberoamericana, sin ceder en su política de exclusividad con Ios PALOP (África lusófona). La tendencia es de superar esa exclusividad porque la geopolítica de los espacios lingüísticos y culturales en el siglo XXI se rige por relaciones policéntricas y soberanas. España no ejerció un "exclusivismo" cuando accedieron a la CPLP: Guinea Ecuatorial como miembro pleno y otros países hispanohablantes y el Consello da Cultura Galega de la Comunidad Autónoma de Galicia como observadores-asociados. El primer ministro portugués celebra:

los movimientos de aproximación que se han dado en ambos sentidos: la creciente cooperación de la Conferencia Iberoamericana con el resto de países de lengua portuguesa y la concesión del estatuto de observador asociado por parte de la CPLP a países de lengua española como Argentina, Chile y Uruguay, así como a la Organización de Estados Iberoamericanos para la Educación, la Ciencia y la Cultura" (Costa, 2019).

La Organización de Estados Iberoamericanos para a Educación, la Ciencia y la Cultura (OEI), durante el periodo 2015-2019, ha ejercido un papel activo de fortalecimiento del proceso objetivo de convergencia iberófona, como espacio multinacional de intercomprensión lingüística panibérica. La OEI, que recientemente estableció una oficina en Lisboa, incorporó como observadores-colaboradores a los países lusófonos africanos y creó una dirección y un programa para la difusión de la lengua portuguesa. En 2017, La directora de la OEI de Portugal, Ana Paula Laborinho, participó en la conferencia del movimento político iberista titulada "Iberofonía e intercomprensión" en Badajoz, ciudad donde existe un tejido asociativo, en pro de un corredor de Sudoeste Ibérico, que haga conectar lenguas, mercancías y pasajeros entre Lisboa y Madrid, por Extremadura, con especial énfasis en el tren de alta velocidad. En 2018, el Organismo Internacional de Juventud para Iberoamérica (OIJ) y la Secretaría General de la Conferencia de Ministros de Juventud y Deporte de la Comunidad de Lengua Portuguesa (CMJD-CPLP) promovieron en Cascais la creación de un "Espacio de la Iberofonía".

La Secretaría General de la Comunidad Iberoamericana (SEGIB) actualmente promueve a través de simposios y sus redes sociales el bilingüismo luso-español. En 2010 se creó la primera universidad panibericamente bilingüe: Ia Universidade Federal da Integração Latino-Americana (UNILA), con sede en la ciudad de la triple frontera de Foz do Iguaçu. Brasil y España firmaron el 8 de noviembre de 2018 un acuerdo en el que se 
comprometen a impulsar la instalación de escuelas bilingües de portugués y español en las zonas de frontera, en una iniciativa de la Organización de los Estados Iberoamericanos (OEI), que también impulsa escuelas-espejo en la Raya peninsular.

Las ideas de Gilberto Freyre encajan perfectamente en la corriente paniberista actual que promueve la Iberofonía. Si -para Gilberto- Brasil era el país más hispánico del mundo, en el sentido de ibérico, hoy podemos decir que es el más iberófono de todos. Freyre se quejaba que Portugal leía pocos libros españoles y los españoles leían aún menos libros portugueses. Solo en Brasil circulaban libros portugueses y españoles con generosidad. Freyre (1975b) afirmó:

Al mundo hispánico (...) no le faltan bases para desenvolverse en una comunidad transnacionalmente hispánica que hasta en la política y la economía - por no hablar de la cultura servida por dos grandes lenguas comunes, la castellana y la portuguesa, y por tres o cuatro menos generales, pero igualmente valiosas e hispánicas- se articule en un sistema de actuación dentro y fuera de sus fronteras y en el que sin extinguirse las semejanzas superen a las diferencias, unidas sin sacrificio de la universalidad, sin sacrificio siquiera de la tendencia a ser al mismo tiempo una y plural, que ha sido siempre tan de los hispanos.

Durántez (2019a) afirma que "se, filologicamente, o espanhol e o português são línguas diferentes, em termos comunicacionais chegam a perceber-se como se fossem practicamente um só idioma". Es decir, se pone en evidencia empírica un espacio lingüístico de intercomprensión. Y en coherencia con ese espacio, surge la propuesta de crear un actor multinacional paniberico en la diplomacia global, Ilamado Iberofonía, concepto geopolítico creado por Frigdiano Álvaro Durántez Prados. La singularidad de dicho espacio lingüístico se justifica porque es "el único caso de dos grandes lenguas internacionales en términos cuantitativos -habladas cada una de ellas por más de cien millones de personas- que son, al mismo tiempo y en líneas generales, recíprocamente comprensibles" (Durántez, 2009). Además, dicho espacio posee otras afinidades substantivas "de naturaleza cultural, histórica, geopolítica y cooperativa", que corresponde "en gran medida al sumatorio de la Comunidad Iberoamericana de Naciones y la Comunidad de Países de Lengua Portuguesa", cuyo conjunto multinacional agrupa a "más de 800 millones de personas y una treintena de países de todos los continentes, que constituye el primer espacio lingüístico del mundo, y que representa la quinta parte de la superficie del planeta, así como la décima en términos demográficos" (Durántez, 2018). 


\section{Las rayas pluricontinentales y la polisemia del bilingüismo}

La frontera histórica entre España y Portugal fue popularmente llamada "Raya". Una "frontera blanda" de ecosistemas culturales y lingüísticos sin rupturas. Y no es una excepción. Existen rayas lingüísticas luso-españolas en el interior de varios continentes y de varias organizaciones intergubernamentales. La Raya americana es la mayor de todas en kilómetros de frontera e en dimensión institucional en el seno de la CIN (Comunidad Iberoamericana de Naciones). La Raya de la Península Ibérica es la más antigua de las fronteras del viejo continente. La Raya africana es tanto de tipo marítimo, entre São Tomé e Príncipe y Guinea Ecuatorial, como institucional en los PALOP y la CPLP. Y, finalmente, la Raya asiática, entre Timor Oriental y las Islas Filipinas, únicos países mayoritariamente católicos de la región.

Los nuevos enfoques de intercomprensión, que ponen énfasis, entre otros aspectos, en la adaptación fonética para los nativos del español y en evitar el uso de falsos amigos en general, parecen ser los más viables para aproximar el espacio lingüístico iberófono. El manual de intercomprensión lectora Interlat utiliza un método de comparación gramatical en tablas para identificar los paralelismos (Tassara y Moreno, 2007). Este manual está inspirado en el Eurom 4, editado en 1997, cuya última versión, Eurom 5 (VV.AA. 2011), incluye cinco lenguas latinas: portugués, español, catalán, italiano y francés. También cabe destacar el actual espacio de formación a distancia del portal MIRIADI que busca crear redes de intercomprensión en internet. Por otro lado, el compromiso de medios de comunicación y editoriales es fundamental para crear una nueva "costumbre" de lectura y audición sin necesidad de traducción o doblaje. Por razones logísticas, la mayoría de cadenas de supermercados etiquetan sus productos en portugués y en español para todo el territorio peninsular. Lo cual ayuda a introducir algún vocabulario de la lengua hermana en casa del país vecino.

¿Cómo podemos conjugar los nuevos enfoques de la intercomprensión con el tradicional y polisémico bilingüismo? Existe una serie de confusiones terminológicas en torno al bilingüismo. Según el diccionario de la Real Academia Española, el bilingüismo es el: "uso habitual de dos lenguas en una misma región o por una misma persona". Para aclarar los debates sobre los desarrollos y aplicaciones del bilingüismo debemos identificar las diferencias entre: el pleno dominio escrito y oral de una lengua no-nativa ibérica, la adquisición de la plena capacidad de intercomprensión, la oficialización estatal de una lengua, la posible estrategia de inmersión lingüística, la política comunicacional interna y externa de las instituciones iberoamericanas o la incorporación obligatoria del portugués o del español a la oferta de lenguas extranjeras en parte de las etapas educativas, sea como asignatura optativa u obligatoria en el currículo escolar. 
La idea general es que cabe una exigencia de pleno dominio escrito y oral de la lengua no-nativa ibérica para áreas fronterizas y para profesionales: diplomáticos, políticos, empresarios y trabajadores, que tengan relaciones con países de la lengua hermana. No se trata de una política de oficializar lenguas hermanas como lenguas de Estado. Tampoco de un bilingüismo educativo uniforme. Establecer una estrategia de inmersión lingüística interdisciplinar, con el español y el portugués como lenguas vehiculares en todo el sistema educativo, puede ser ineficiente por el tamaño de la población objetivo, las limitaciones presupuestarias y el despilfarro de energías por desaprovechar las ventajas de la intercomprensión lingüística.

Para Durántez (2019b) la política lingüística compartida en ese espacio sería suficiente con el: "reforzamiento de la intercompresión recíproca. Y no sólo en el ámbito iberoamericano. Esto se conseguiría con la respectiva enseñanza temporal de ambos idiomas durante la etapa escolar". El Partido Ibérico Íber propuso para España y Portugal la implantación de una asignatura: "Lenguas Ibéricas", en primaria y secundaria, optativa para los alumnos, pero de obligada oferta para los centros educativos, como "un instrumento eficaz para el buen entendimiento entre ibéricos". La Plataforma por la Federación Ibérica ha solicitado recientemente la inclusión opcional del portugués como segunda lengua extranjera en el sistema educativo madrileño, tal y como ya existe en Galicia (Ley Paz-Andrade) y en Extremadura.

Además de las confusiones terminológicas aquí desarrolladas, existe otra confusión en relación con las políticas de promoción de las lenguas en el interior y el exterior del espacio panibérico (iberofonía). Es importante diferenciar: 1) Una política lingüística para los sistemas educativos e institucionales de los países de lengua portuguesa y española; 2) Una política lingüística para ampliar los hablantes del portugués y el español allí donde no se habla portugués ni español. Ambas deben ser diplomáticamente consensuadas. El 21 de enero de 2019, durante un evento en Lisboa, el Instituto Cervantes (IC) ofreció su infraestructura global "no solo enseñar portugués en el Cervantes sino también para propagar la cultura y las lenguas de toda la península ibérica", enfatizando la apertura plena de las 87 sedes a las iniciativas del Instituto Camões, como así afirmó el director del IC, García Montero, además de anunciar un próximo estudio sobre el poder conjunto de las lenguas ibéricas. Según el director del IC de Rio de Janeiro, Antonio Maura: "lo que se refiere a la enseñanza del idioma creo que deberían ponerse de acuerdo los Institutos Camões y el Cervantes con vista a una enseñanza colegiada en los países que no sean de habla ni española ni portuguesa”. Y añadió: “las dos lenguas van a hermanarse aún más. La reciente exposición Camões-Cervantes no hace sino recalcar estas similitudes tan ibéricas. Pensar de otra forma, en mi opinión, es negarse 
a un futuro necesario y a un pasado donde no existieron ese tipo de diferencias". Un futuro que para Maura está "en la reconstrucción de la Unión Ibérica, ahora desde patrones democráticos" (Maura, 2019).

\section{Las fronteras policentricas de la intercomprensión}

Es una evidencia empírica que todo nativo hispanohablante de visita a un país lusófono se hace entender más que lo que entiende. El nativo lusófono, sin embargo, entiende más de lo que se hace entender en la hispanofonía. Según constata Durántez (2019c): "el español es comprendido de modo generalizado en los países de lengua portuguesa, de modo que nuestro idioma amplía sustancialmente su base objetiva en cerca de un 40\%". También el "lusófono nativo se beneficia de una ventaja subjetiva a la hora de comprender el castellano". Por tanto, la comprensibilidad nativa del lusófono se duplica ampliamente al considerar el territorio hispanohablante. ¿Y el idioma portugués? ¿es entendido por el hispanohablante?

En 1956, durante una conferencia de Freyre (1965) en El Escorial, los estudiantes le confesaron que le entendían mejor a que a los portugueses. Una anécdota parecida se produjo en la Universidad de Columbia cuando: "Um catedrático espanhol disse-me um dia (...): compreendo seu português melhor que os dos meus vizinhos de Portugal, que comem metade das palavras, e melhor -acrescentou com um sorriso- que o espanhol de alguns americanos de América espanhola". Maura (2019) afirma: "Pienso que el portugués que se habla en Brasil es mucho más parecido del español que el que se habla en Portugal. Eso daría para un estudio lingüístico interesante". Durántez (2019a) señala que: "o português, particularmente o de Portugal, se entende en menor grau, por razões fonéticas nos países hispânicos.".

La intercomprensión escrita y oral, en líneas generales, es recíproca en todos los países de lengua portuguesa y española. Mientras que la intercomprensión escrita es simétrica, la oral es asimétrica y tiene una excepción geográfica. La asimetría oral se explica porque la fonética española cabe dentro de la portuguesa, pero desconoce algunos sonidos del portugués. Otro factor de asimetría es el aprendizaje: la mayor presencia internacional del español y en el sistema educativo lusófono les hace estar más familiarizados. La intercomprensión oral, además de fonéticamente asimétrica, tiene una excepción: el portugués de Portugal es ininteligible oralmente para el hispanohablante.

Esta excepción del portugués europeo ( $4 \%$ del portugués global) crea un espejismo eurocéntrico sobre el grado de comprensibilidad oral del portugués global por parte del hispanohablante. Esta oralidad ininteligible lusa representa un $1 \%$ de los hablantes del conjunto de la iberofonía (800 millones). 
Por la mayor presencia nativa y comunicacional internacional y por el mayor tamaño del espacio de comprensión oral, el castellano estaría llamado a ser la lengua ibérica más eficiente de comunicación en el espacio pan-ibérico y fuera del mismo. Sin embargo, la cultura de la intercomprensión lo que promueve es que cada uno se exprese con total comodidad y libertad en su lengua nativa ibérica. Cabe resaltar que la variedad del portugués mundialmente mayoritaria es la brasileña (80\%), que es más neutral, más vocalizada y abierta, por la influencia de las lenguas africanas, y, en menor medida, por el español (Freyre, 2010, p. 327 [1933]). Es el "portugués con azúcar" (Queiroz, 1872).

El portugués africano (10\% del portugués global) es gramaticalmente más cercano al de Portugal, pero fonéticamente no es tan cerrado como el peninsular, de hecho, los fonemas pronunciados por los angoleños se asemejan en algunos casos al acento del hispanohablante hablando en portugués. Las comunidades portuguesas en el exterior por su contacto con lenguas extranjeras su acento se atenúa a oídos de los hispanohablantes. Por tanto, es posible decir que el $96 \%$ del portugués global es substancialmente comprensible en su oralidad, a pesar de que su grado comprensibilidad oral, para un hispanohablante, siempre será inferior al del lusófono cuando escucha la lengua española.

La ininteligibilidad oral luso-europea es corregible por dos vías: 1) Que el hispanohablante tenga una exposición continuada a la pronunciación Iusa del portugués; 2) Que el lusófono europeo incorpore progresivamente un trazo fonético más aproximado de la pronunciación brasileña, que de hecho, ya está siendo expuesto a dicha influencia por la inmigración, las telenovelas y la globalización de las comunicaciones; sin que ello suponga necesariamente un menoscabo del rico patrimonio lingüístico y regional luso.

\section{La ley del español en Brasil: una experiencia no-bilingüista}

La ley del español correspondió a un movimiento diplomático de liderazgo para la integración latinoamericana y de aproximación a la comunidad iberoamericana. Su revocación correspondió a un movimiento en sentido opuesto: un alejamiento regional y una aproximación a los Estados Unidos.

La ley brasileña del español (Brasil, 2005) no establecía un sistema educativo bilingüe luso-español, tal y como entendemos el bilingüismo en España con las lenguas cooficiales o con el inglés u otras lenguas extranjeras. El bilingüismo en el sistema educativo implica una inmersión lingüística interdisciplinar, repartiendo las asignaturas convencionales (no 
lingüísticas) en dos o tres lenguas vehiculares. La ley del español en Brasil establecía la asignatura lingüística del español como lengua extranjera: "O ensino da língua espanhola, de oferta obrigatória pela escola e de matrícula facultativa para o aluno, será implantado, gradativamente, nos currículos plenos do ensino médio".

Esta ley fue revocada por el presidente Michel Temer por otra en la que "Os currículos do ensino médio incluirão, obrigatoriamente, o estudo da língua inglesa e poderão ofertar outras línguas estrangeiras, em caráter optativo, preferencialmente o espanhol, de acordo com a disponibilidade de oferta, locais e horários definidos pelos sistemas de ensino" (Brasil, 2017).

Con papeles intercambiados entre "el grande" y "el pequeño", se reproduce en América la herencia peninsular de vivir de espaldas del mundo luso y el mundo hispano. El latinoamericanismo, presente en la constitución brasileña, no deja de ser una forma de iberismo intra-americano contemporáneo. Al contrario de la frontera luso-española, la comunicación transfronteriza en la frontera hispanoamericana-brasileña se realiza, con algunas excepciones, en portugués brasileño o en portuñol. La ley del español tuvo un notable impacto en el sistema educativo brasileño, aunque no fuese completamente aplicada en el tiempo que estuvo en vigor. Su revocación no implica la desaparición automática de dicho impacto.

El movimiento asociativo de profesores y alumnos "Fica Espanhol" ha conseguido algunos éxitos. Diferentes Estados brasileños, situados cerca de la frontera, están garantizando la enseñanza del español. En el sector privado siempre hubo una permanente demanda de aprendizaje de español, especialmente de trabajadores brasileños en empresas españolas y de otros sectores económicos relacionados con el Mercosur. Dicha demanda hoy se encuentra resentida por la crisis económica.

TeleSur, canal multiestatal liderado por Venezuela, llegó a tener telediarios en portugués. El proyecto de EBC, televisión pública brasileña, que finalmente se implementó de manera más limitada, llegó a barajar la emisión en portugués para toda América Latina. En la televisión pública de Extremadura (España) existe un programa de enseñanza del portugués " $\mathrm{Fa}$ lamos Português" y otros programas en televisión y radio sobre los vecinos lusos como "Lusitania Express". La emisión de canales en ambas lenguas en todos los países de la iberofonía es una tarea pendiente e, incluso, la propia articulación de un canal como IBE.TV, canal de televisión de la SEGIB para las redes sociales, con contenidos tanto en español como en portugués. 
La política externa de Cuba ha generado un importante legado iberófono en los países de lengua portuguesa, y en la propia Cuba, tanto por sus misiones militares, médicas o de alfabetización, como por sus becas a estudiantes lusófonos en la Habana, con especial impacto en Angola, Cabo Verde, Mozambique y Brasil.

\section{Una comunidad sin excepciones: de Iberoamérica a la Iberofonía}

Cuatro años después de la muerte de Freyre nació en México la comunidad iberoamericana de jefes de Estado "con la participación de los Estados soberanos de América y Europa de lengua española y portuguesa" (CIN, 1991). Un sueño cumplido post mórtem, que Freyre ya había explicitado en 1957 y asumido al ser miembro de honor del Instituto de Cultura Hispánica a partir del 12 de octubre de 1955. No obstante, se trata de un sueño incompleto porque faltan en esa comunidad (iberoamericana) los jefes de Estado de lengua española y portuguesa de África y Asia. Sólo así podrá articularse el conjunto panibérico, que hoy es Ilamado de "Iberofonía", aspiración final de Gilberto Freyre.

La escritora portuguesa Correia (1988), admiradora de Freyre, reconocía la existencia de una "comunidade cultural ibero-afro-americana". "Uma comunidade hispânica pluricontinental". "Uma constelação ibérica euro-afro-americana. Constituindo uma das maiores comunidades linguísticas e culturais". Idea mucho más inclusiva que la "Hispanidad", cuyas fronteras siempre fueron difusas. Barcia (2008) prefiere el término de "Iberidad". En la misma línea, Chacon (2005), discípulo de Freyre, propone la "Grande Ibéria": "na perspectiva brasileira da Nova Ibérica continental americana à Antiga Ibéria peninsular europeia, ida e volta: encontros, desencontros e reencontros pelos oceanos das Áfricas e Ásias lusófonas e hispanófonas até Oceania das Filipinas e Timor Leste" y cita a Durántez Prados "quando apresentou nas II Jornadas de Relações Internacionais da Universidade Lusíada de Porto, no ano 2000, considerações sobre a necessidade e importância da articulação entre a Comunidade Ibero-Americana de Nações - CIN e a Comunidade dos países de Língua Portuguesa - CPLP".

Según el geopolitólogo Durántez (2014), las características lusotropicales descubiertas o imaginadas por Freyre son “también aplicables, en líneas generales y sin discriminación, al conjunto del mundo hispánico, o hispanotropical, que engloba y contiene al lusotropical, al estrictamente de colonización portuguesa". Incluso Freyre va más allá, proponiendo una "federação de cultura". Lo que encaja con el actual "planteamiento geopo- 
lítico y cooperativo" de "asociación de los países de lenguas ibéricas del mundo, sin exclusiones geográficas". Dicho de otro modo: una "articulación de un espacio multinacional de países de idiomas ibéricos", cuya propuesta y tendencia ha sido denominada con las "expresiones iberofonía y espacio iberófono". Se trata de la "segunda y definitiva convergencia multinacional iberófona" (Durántez, 2018). La primera fue Iberoamérica.

Para Freyre, la defensa del espacio pan-ibérico no era contradictoria con la convergencia lusófona, que finalmente fue posible nueve años después de su muerte, la CPLP (Comunidad de Países de Lengua Portuguesa). Como otro sueño anticipado, auguró la importancia de los sistemas de cultura supranacionales, entre ellos, el más natural sería el hispánico (ibérico):

Si entre las modernas culturas hay una cultura de gran porvenir es la iberoamericana. Mientras esta cultura siga siendo ibérica o hispánica, en vez de fraccionarse en treinta reinos de Taifas de la cultura, los pueblos hispánicos de Europa y los de creación hispánica diseminados por América y otras partes del mundo formaremos un -por decirlo así- natural sistema de cultura con sus condiciones de unidad, sin perjuicio de su diversidad. En una época en que los pueblos menos afines entre sí que los nuestros están intentando por todos los medios articularse en federaciones o uniones -un tanto artificiales algunas de ellas-, a los pueblos hispánicos sólo nos resta la tarea de completar la labor ya realizada por un pasado que es esencialmente el mismo para los hispanos de América, de Europa, de Oriente y de África: el pasado hispánico (Freyre, 1957).

Freyre (1961) propondrá una "comunidade federada" en el artículo Brasil, líder da civilização tropical:

[Brasil] seria a grande nação mediadora entre a América, a África e a Europa. Não vejo por que essa missão não possa vir a ser desempenhada pelo Brasil. Em certo sentido, e à revelia de políticos brasileiros ainda arcaicos em seus métodos de fazer política, é uma missão que já está sendo desempenhada pela cultura brasileira através dos seus Villa-Lobos, dos seus arquitetos modernos, dos seus pintores atuais, de alguns dos seus modernos pensadores e cientistas sociais. Mas para cumprir essa missão, no melhor sentido da palavra platônica, pensam alguns sociólogos brasileiros caber ao Brasil, agir, antes, aristotelicamente, isto é, pragmaticamente e articular-se com os demais povos hispano-tropicais, em geral, e luso-tropicais, em particular - povos que já não são particularmente latinos porém vêm juntando a uma herança multieuropéia valores de culturas tropicais, ameríndias, africanas e asianas, através de métodos especificamente hispânicos de interpenetração - numa possível comunidade federada.

Brasil, junto con la iberofonía, podría convertirse en una "China Tropical", que "hable de igual a igual" al mundo anglosajón" (Freyre, 1976). El poder de arrastre panibérico de Brasil y la África lusófona siempre será 
más fuerte que las posibles renuencias lusas. Un Brasil panibérico puede asumir ese liderazgo, hipótesis que no es, según Freyre (2001), un ejercicio arcaico de quijotismo o sebastianismo, sino puro pragmatismo ganador para todas las partes y para ambos idiomas.

\section{Referencias bibliográficas}

Barcia, M. (2009). Geopolítica de la Iberidad. Madrid: Dykinson.

Brasil (2005). Leinº 11.161/2005(lei ordinária) 05/08/2005. Disponible en https://bit.ly/33AjEc3

Brasil (2017). Lei $n^{\circ} 13.415$, de 16 de fevereiro de 2017. Disponible en https://bit.ly/31zjteY

Chacon, V. (2005). A grande Ibéria: convergências e divergências de uma tendência. SciELOEd. UNESP. Disponible en https://bit.ly/2YKsVze

CIN (1991). Primera Cumbre Iberoamericana de Jefes de Estado y de Gobierno. México: Declaración de Guadalajara.

Correia, N. (1988). Somos Todos Hispanos. Portugal: Notícias Editorial. Disponible en https:// bit.ly/2ZZMfoZ

Costa, A. (2019). Iberoamérica y la lengua portuguesa. Suplemento Le Monde Diplomatique. España: SEGIB. Disponible en https://bit.ly/31MUzJh

Durántez, F.A. (2009). Paradigma y ciclo de Hispania. Madrid: Sepha.

Durántez, F.A. (2014). Paralelismos y convergencias entre la comunidad iberoamericana de naciones y la comunidad de países de lengua portuguesa:i existe un espacio multinacional de países de lenguas ibéricas? (Doctoral dissertation, Universidad Complutense de Madrid). Disponible en https://bit.ly/2YQmB9F

Durántez, F.A. (2019a, 28 de marzo). Angola e a Iberofonia. Jornal de Angola. Disponible em https://bit.ly/2YPSkrm

Durántez, F.A. (2019b, 9 de enero) Entrevista a Álvaro Durántez: “El español y portugués son la clave de un nuevo actor global panibérico". ABC. Disponible en https://bit.ly/2H67WfA

Durántez, F.A. (2019c, 30 de marzo). El español, pilar de la iberofonía y lengua universal. ABC. Disponible en https://bit.ly/2N1te1J

Durántez. F.A. (2018). Iberofonía y Paniberismo. Definición y Articulación del Mundo Ibérico, España: Última Línea.

Felipe VI (2018, 15 de noviembre) Palabras de Su Majestad el Rey en la Clausura del XII Encuentro Empresarial Iberoamericano. Guatemala: Casa Real. Disponible en https://bit.ly/302vCsH

Figueiredo, F. de (1935). Pyrene. Introducción a la historia comparada de las literaturas portuguesa y española

Freyre, G. (1953). Aventura e rotina: sugestões de uma viagem à procura das constantes portuguêsas de caráter e ação. Brasil: J. Olympio.

Freyre, G. (1957). Notas sobre la Cultura Hispánica. Revista Cuadernos Hispanoamericanos, $n^{\circ}$ 85. Madrid: ICH. Disponible en https://bit.ly/30mrMec 
Freyre, G. (1961, 22 de julio). Brasil, líder da civilização tropical. O Cruzeiro.

Freyre, G. (1965, 2 de julio). No Instituto Hispânico da Universidade de Columbia. O Cruzeiro.

Freyre, G. (1968). Como e porque sou e não sou sociólogo. Brasil: Ed. da Universidade.

Freyre, G. (1971). A propósito de cultura hispânica como cultura transnacional projetada sobre o futuro. Revista Brasileira de Cultura, 9. Rio de Janeiro: Conselho Federal.

Freyre, G. (1975a). Tempo morto e outros tempos: trechos de um diário de adolescência e primeira mocidade, 1915-1930. Olympio. (2012). Ed. Digital.

Freyre, G. (1975b). Mexicanos, brasileños y el mundo hispánico. Norte: Revista Hispano Americana, 263, 37-40.

Freyre, G. (1976, 23 de septiembre). Rueda de prensa de GF. Madrid: Audio Biblioteca Hispánica AECID. Disponible en https://bit.ly/33SgfFk

Freyre, G. (2001). Antecipações. Edson Nery da Fonseca (coord.). Brasil: EDUPDE.

Freyre, G. (2010 [1933]). Casa-grande y senzala. La formación de la familia brasileña en un régimen de economía patriarcal. Madrid: Marcial Pons / Fundación Cultural HispanoBrasileña. Disponible en https://bit.ly/2z87Xet

Marías, J. (1981). El tiempo y lo hispánico en Gilberto Freyre. Tiempo muerto y otros tiempos. Cuenta y razón, (2), 7-16. Disponible en https://bit.ly/20VscqC

Marías, J. (1983, 2 de octubre). Gilberto Freyre y la imaginación. La Vanguardia. Disponible en https://bit.ly/20UeZ1i

Marías, J. (1988). Gilberto Freyre en el Mundo Hispánico. A memória de Gilberto Freyre. Brasil: Massangana.

Maura. A. (2019, 7 de febrero). Entrevista a Antonio Maura. Madrid: Blog Estado Ibérico. Disponible en https://bit.ly/2yZC4oi

Piñon, N. (2010). Los lazos entre las lenguas portuguesa y española. Español y portugués: lenguas en convivencia. Congreso de Valparaíso. Disponible en https://bit.ly/2KNBCzf

Queiroz, E. de (fevereiro de 1872). Jornal As Farpas, pág. 86. Disponible en https://bit.ly/2KCbk3U

Reyes, A. (1952). Teoría de la antología. La experiencia literaria, 3, 129-133

Rodil, L. (2019). Documental: Salamanca-Coimbra, espejo del conocimiento. Castilla y León Televisión.

Silva, A.S. (2018, 20 de noviembre). Nós, ibero-americanos. Diário de Notícias. Disponible en https://bit.ly/33wG1iv

Santos, J.M. (2019, 11 de mayo). Entrevista a José Manuel Santos. Madrid: Blog Estado Ibérico. Disponible en https://bit.ly/2Z6gTzD

Tassara, G. y Moreno, F. (2007). Manual INTERLAT. Comprensión escrita en portugués, español y francés. Chile: Ediciones Universitarias de Valparaíso. Disponible en https://bit. ly/2zem0iV

Valera, J. (1861, 15 de diciembre). España y Portugal. Revista Ibérica. I(V), 349-362. Disponible en https://bit.ly/31BORcX

VV.AA. (2011). EUROM 5. Leer y entender 5 lenguas románicas, España: Sociedad General Española Librería. 